\title{
Functional outcome and patient satisfaction following LASIK surgery
}

\author{
Dipak B. Patel', Anjasi M. Patel ${ }^{2, *}$, Mohak A. Shah ${ }^{3}$, Aneesha K Vyas ${ }^{4}$, Shail Shah ${ }^{5}$ \\ ${ }^{\mathbf{1}}$ Professor, ${ }^{\mathbf{2}, \mathbf{4}}$ Resident, ${ }^{\mathbf{3}}$ Assistant Professor, Dept. of Ophthalmology, SBKS Medical Institute \& Research Center Sumandeep \\ Vidyapeeth, Vadodara, Gujarat, India
}

*Corresponding Author: Anjasi M. Patel

Email: dr.anjasi.patel@gmail.com

\begin{abstract}
Aims: The purpose of the study was to evaluate the functional gain, visual outcome and patient satisfaction after LASIK. Materials and Methods: The study included 150 patients (85 males and 65 females) that underwent LASIK procedure for correction of refractive error and were followed up on first week, first and third month postoperatively. Visual acuity, Schirmer's test and contrast sensitivity were evaluated on each follow up. The patients were asked to fill a questionnaire consisting of 14 questions scored as 0,1 and 2 for an unsatisfied, satisfied and very satisfied patient respectively prior to surgery and on the last visit. The patients were divided into three groups on the basis of the score obtained as: $(<10)$ for unsatisfied, (11-20) for satisfied and (21-28) for a very satisfied patient.

Results: In this study, the UCVA in $98.6 \%$ of our patients was $\geq 20 / 30$ postoperatively. The mean Schirmer's I value was $13.99 \pm$ 1.530 in the right eye and $14.01 \pm 1.544$ in the left eye, while Schirmer's II values were $13.44 \pm 2.128$ and $13.51 \pm 2.351$ in the right and left eye respectively at the end of 3 months. Contrast sensitivity improved to a mean of $1.79 \pm 0.15$ at three months. Night driving complications reduced from a mean score of $1.59 \pm 0.29$ to $0.58 \pm 0.05$ postoperatively.

Conclusions: High level of patient satisfaction can be attained with LASIK procedure. Night vision problems and dry eye are imperative causes of dissatisfaction.
\end{abstract}

Keywords: LASIK, Patient satisfaction, Refractive error.

\section{Introduction}

Laser-Assisted In Situ Keratomileusis (LASIK) has drastically emerged as a modality for the correcting refractive errors and is currently the most frequently performed refractive surgery. ${ }^{1,2}$ The surgical outcomes of LASIK are safe and predictable. The purpose of this study is to assess functional outcome and patient satisfaction after LASIK. Quality of life indicators helps us understanding the trivial factors causing dissatisfaction to the patients which can help practitioners to better counsel the patients and improve surgical planning.

\section{Materials and Methods}

All the patients undergoing LASIK surgery who met the study related inclusion and exclusion criteria from October 2016 to February 2017 at the department of Ophthalmology, Sumandeep Vidyapeeth were included in the study. The approval of Sumandeep Vidyapeeth Institutional Ethics Committee was obtained in September 2016 before commencement of the study.

Patients with myopia of $>8 \mathrm{D}$, hypermetropia of $>6 \mathrm{D}$ and astigmatism of $>4 \mathrm{D}$, pachymetry less than 470 microns, having unstable refraction $(>0.5 \mathrm{D}$ change in last 1 year), estimated RST (Residual Stromal Thickness) below 280 microns, intra operative complications, undergoing re-LASIK and/or LASIK surgery without full correction, having history of corneal surgery in past, preoperative dry eye, ectatic corneal disorder like keratoconus; glaucoma, cataract, retinal abnormalities like macular hole, retinal detachment; systemic abnormalities like renal failure, leukemia, rheumatism, allergy, degenerative or autoimmune diseases; as well as pregnant $\&$ nursing patients were excluded from the study.

Out of the 180 patients that were screened, 30 were lost to follow up. A total of 300 eyes of 150 patients between the age of 18 to 30 years undergoing LASIK surgery for full correction of refractive error were included in the study. All the enrolled patients underwent complete ophthalmic examination. The visual status assessed was inclusive of Uncorrected (UCVA) and Best Corrected Visual Acuity (BCVA) for distance along with carrying out cycloplegic and non-cycloplegic refraction using Snellen's visual acuity chart. Intraocular Pressure (IOP) was measured using Non-Contact Tonometry (NCT). Complete examination of the anterior segment was performed using slit lamp biomicroscopy. Those patients with a history of contact lens wear were asked to discontinue lenses atleast 2 weeks prior to the evaluation. Corneal topography and wave front was performed using the ATLAS of Carl Zeiss Meditec and Oculus Pentacam. Pachymetric evaluation was done with the help of the ultrasound pachymeter (Accutom) and Oculus Pentacam. For the assessment of patient satisfaction and visual outcome various parameters were considered. Amidst these, contrast sensitivity was determined using Pelli-Robson contrast sensitivity chart. Schirmer's test I and II was performed for the quantitative analysis of the tear film.

Thereafter, detailed fundus examination was done with slit lamp biomicroscopy using $90 \mathrm{D}$ or $78 \mathrm{D}$ lens and/or indirect ophthalmoscopy with the help of a 20D lens after the use of mydriatic agents.

During the surgery, a corneal flap of $6 \mathrm{~mm}$ optical zone was made with a superior hinge with the help of a 
Moria M3 evolution microkeratome. The Carl Zeiss Mel 80 excimer laser was used for ablation. The stability of the corneal flap and adherence to the corneal stroma was re-evaluated at 2 hours postoperatively. Following the surgery, the patients were started on topical steroid, topical antibiotic and topical lubricating eye drops along with the use of anti-glare protective goggles.

Post operatively the patients were evaluated on day 7, 1 month and 3 months. On every visit the visual acuity, Schirmer's test and contrast sensitivity were evaluated. In addition to the ocular examination, the patient satisfaction evaluation form was made to be filled by each patient preoperatively and at the last follow up. It consisted of a questionnaire comprising 14 questions given in [Table 1]. The patients were asked to choose between three options: very satisfied, satisfied and unsatisfied which were allotted 2, 1 and 0 points respectively. The total score from all 14 questions was calculated and divided into a range of three: <10, 11-20 and 21-28 interpreted as the patient being unsatisfied, satisfied and very satisfied respectively.

Table 1: Questions for evaluation of patient satisfaction

\begin{tabular}{|l|l|}
\hline S. No. & \multicolumn{1}{c|}{ Question } \\
\hline 1 & Night driving \\
\hline 2 & Glare and halos \\
\hline 3 & Reading Traffic Lights \\
\hline 4 & Watching Television \\
\hline 5 & Reading Newspaper \\
\hline 6 & Computer work \\
\hline 7 & Doing fine handwork \\
\hline 8 & Eye strain \\
\hline 9 & Pain \\
\hline 10 & Watering \\
\hline 11 & Foreign body sensation \\
\hline 12 & Burning sensation \\
\hline 13 & Problem with bright sunlight \\
\hline 14 & Problems while swimming \\
\hline
\end{tabular}

\section{Data Analysis}

All the qualitative data were presented in numbers and percentage. Quantitative data were presented in Mean \pm SD. Repeated measures ANOVA test was used to find statistical mean difference of the Schirmer's I and II as well as contrast sensitivity from baseline to postoperative three months. $\mathrm{p}$ value $<0.05$ was considered statistically significant.

\section{Results}

The study included a total of 150 patients out of which $65(43.33 \%)$ were females and 85 (56.67\%) were males. Patients enrolled were in the age group between 18 and 30 years with a mean age of $23.76 \pm 2.91$ years. The mean age of the female patients was $23.28 \pm 2.55$ years and that of the males was $24.17 \pm 3.18$ years.
Amongst the total patients, 39 (26\%) were skilled workers, $35(23.33 \%)$ were unskilled workers, 39 $(26.00 \%)$ were homemakers, $24(16 \%)$ were into business and $13(8.67 \%)$ were unemployed. On reasoning with the patients regarding the motivation to undergo this surgical procedure, 55 (36.67\%) were undergoing LASIK for better marriage prospects, 28 $(18.67 \%)$ for meeting with their job requirements, 41 $(27.33 \%)$ for independency from glasses and 26 $(17.33 \%)$ were getting the procedure for cosmetic reasons.

The patients undergoing LASIK procedure had myopia, hypermetropia, astigmatism (myopic or hypermetropic) or a combination of these refractive errors. The mean duration of use of spectacle correction in these patients was $6.69 \pm 3.43$ years. Of these, 28 $(18.67 \%)$ patients gave an occasional history of Soft Contact Lens (CL) wear for a duration of $3.13 \pm 2.5$ years. The patients were asked to discontinue CL wear for at least 2 weeks prior to the preoperative work up. The mean preoperative refractive error in the myopic patients was $-6.95 \pm 0.65 \mathrm{D}$ and in the hypermetropic patients was $+5.45 \pm 0.25 \mathrm{D}$. Out of the patients having astigmatism, the mean myopic astigmatism was $-2.98 \pm$ $0.86 \mathrm{D}$ and the mean hypermetropic astigmatism was $+3.25 \pm 0.26 \mathrm{D}$.

The mean Central Corneal Thickness (CCT) of the patients preoperatively measured using ultrasonic pachymeter was $526.61 \pm 27.75 \mu \mathrm{m}$ in the right eye and $522.55 \pm 27.36 \mu \mathrm{m}$ in the left eye, while mean CCT as measured on Oculus Pentacam was $524.49 \pm 27.60 \mu \mathrm{m}$ and $521.79 \pm 27.06 \mu \mathrm{m}$ in the right and left eye respectively. The mean $\mathrm{K}_{\text {steep }}$ and $\mathrm{K}_{\text {flat }}$ in the right eye preoperatively was $44.28 \pm 1.66 \mathrm{D}$ and 43.38 $\pm 1.20 \mathrm{D}$. The mean $\mathrm{K}_{\text {steep }}$ and $\mathrm{K}_{\text {flat }}$ was $44.65 \pm 1.70 \mathrm{D}$ and $43.48 \pm$ $1.22 \mathrm{D}$ in the left eye. The mean optical zone for ablation was $5.75 \pm 0.25 \mathrm{~mm}$.

On comparing the postoperative UCVA with the preoperative BCVA, 4 patients $(2.67 \%)$ had a gain of 2 lines, $19(12.67 \%)$ patients had a gain of 1 line and 127 $(84.67 \%)$ of the patients had the same visual acuity pre and post-operatively at the end of the first month after surgery. Amongst these, at the third postoperative month, $4(2.67 \%)$ had a two line gain, $20(13.33 \%)$ had a 1 line gain and $126(84 \%)$ had maintained visual acuity [Table 2]. No patients had postoperative loss of vision. The mean postoperative myopic refractive error was $0.66 \pm 0.03 \mathrm{D}$ and that for hypermetropia was $+0.42 \pm$ $0.06 \mathrm{D}$ on three months follow up. The postoperative myopic astigmatism was $-0.23 \pm 0.01 \mathrm{D}$ and hypermetropic astigmatism was $+0.43 \pm 0.04 \mathrm{D}$.

Baseline tear film evaluation of the patients was done using Schirmer's I and II test and Tear Film Break Up Time (TBUT), which was within normal limits. The mean Schirmer I test in the right eye was $12.84 \pm 2.428$ $\mathrm{mm}, 13.55 \pm 1.937 \mathrm{~mm}$ and $13.99 \pm 1.530 \mathrm{~mm}$ on the seventh day, one month and three months postoperatively as shown in [Fig. 1]. On the other hand 
Schirmer's I in the left eye was $12.86 \pm 2.439 \mathrm{~mm}$, $13.57 \pm 1.950 \mathrm{~mm}$ and $14.01 \pm 1.544 \mathrm{~mm}$ respectively. The mean Schirmer's II test in the right was $12.23 \pm$ $3.123 \mathrm{~mm}$ on the POD (postoperative day) seven, 12.84 $\pm 2.469 \mathrm{~mm}$ at one month and $13.44 \pm 2.128 \mathrm{~mm}$ on the third postoperative month and the same in the left eye was $12.25 \pm 2.351 \mathrm{~mm}, 12.82 \pm 2.474 \mathrm{~mm}$ and $13.52 \pm$ $2.351 \mathrm{~mm}$ respectively. These results were statistically significant with $\mathrm{p}$ value of 0.001 .

Contrast sensitivity of the patients at baseline (preoperatively) was $1.54 \pm 0.23$. This increased to 1.55 \pm 0.18 on the seventh postoperative day and was $1.79 \pm$ 0.14 and $1.79 \pm 0.15$ at one and three months postoperatively [Fig. 2]. Hence, a significant improvement in contrast sensitivity of the patients was seen after LASIK surgery. ( $\mathrm{p}$ value: 0.001 ).

Patient satisfaction score was evaluated on the basis of a questionnaire comprising of 14 questions as shown in [Table 1] filled at baseline and on third follow up. The mean preoperative patient satisfaction score was $15.32 \pm$ 3.25 which increased to $22.49 \pm 2.85$ postoperatively. Of the various parameters evaluated the patient satisfaction in night driving was $1.59 \pm 0.29$ preoperatively which deteriorated to $0.58 \pm 0.05$ postoperatively. The patients complained more of glares and halos after the procedure with a mean satisfaction score of $1.45 \pm 0.17$ preoperatively reducing to $0.60 \pm 0.07$ postoperatively. Visualisation of the traffic signal improved from $0.65 \pm$ 0.1 to $1.45 \pm 0.25$ postoperatively. Satisfaction score of watering was $0.54 \pm 0.06$ preoperatively and $1.35 \pm 0.3$ postoperatively. Clarity on watching television went from $0.78 \pm 0.08$ to $1.58 \pm 0.21$ at the end of three months. Though for those working on the computer, the patient satisfaction was reduced from $1.65 \pm 0.23$ to 0.76 \pm 0.08 postoperatively. Other parameters on the questionnaire did not show a significant change before and after surgery.

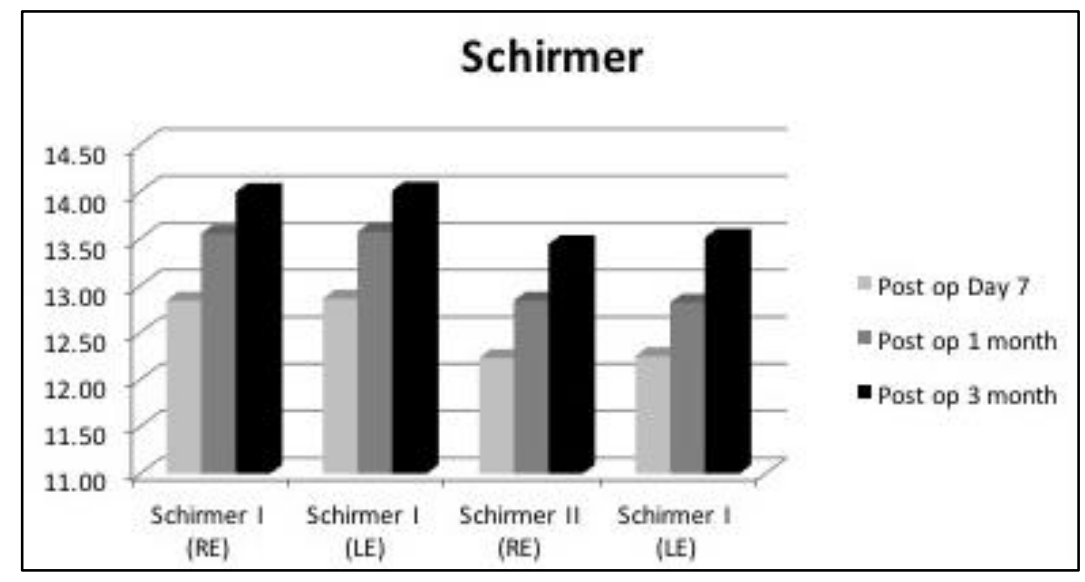

Fig. 1

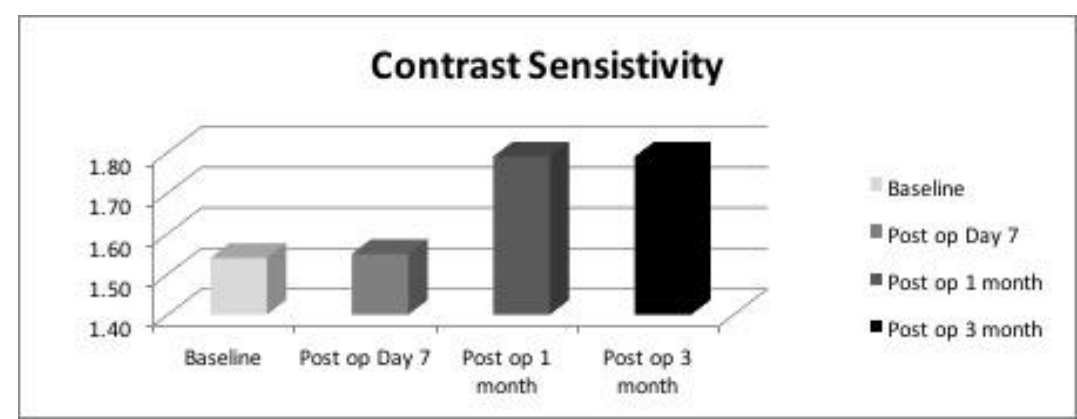

Fig. 2

Table 2: Comparison of postoperative uncorrected visual acuity (UCVA) to the preoperative best-corrected visual acuity (BCVA)

\begin{tabular}{|l|c|c|c|c|}
\hline \multirow{2}{*}{ BCVA Line } & \multicolumn{2}{|c|}{ Post op 1 month } & \multicolumn{2}{c|}{ Post op 3 months } \\
\cline { 2 - 5 } & $\begin{array}{c}\text { Post op UCVA Vs } \\
\text { Pre op BCVA }\end{array}$ & $\%$ & $\begin{array}{c}\text { Post op UCVA Vs } \\
\text { Pre op BCVA }\end{array}$ & $\%$ \\
\hline Gain 2 Lines & 4 & $2.67 \%$ & 4 & $2.67 \%$ \\
\hline Gain 1 Line & 19 & $12.67 \%$ & 20 & $13.33 \%$ \\
\hline Maintain & 127 & $84.67 \%$ & 126 & $84.00 \%$ \\
\hline Total & 150 & $100.00 \%$ & 150 & $100.00 \%$ \\
\hline
\end{tabular}




\section{Discussion}

The constant inflation in the health care costs have compelled the government to ensure assessment of value purchasing and performance measurement during the delivery of health care services. One of these parameters is the assessment of patient satisfaction which is considered to be a qualitative analysis of the treatment provided. Therefore, feedback about the quality of care as well as surgical outcomes can be obtained from such studies and shall assist us in modifying the existent treatment modalities. ${ }^{3}$ According to various studies that evaluated the patient satisfaction, $82 \%$ to $98 \%$ of the patients were satisfied after surgery. ${ }^{4-6}$

Several studies have also discussed regarding the increased efficacy, safety, and predictability of surgical outcomes after LASIK. ${ }^{7}$ In this study, the UCVA in $98.6 \%$ of our patients was $\geq 20 / 30$ postoperatively. While improvement in the postoperative uncorrected visual acuity maybe the ultimate goal of the patients, a 20/20 vision may also leave the patient unsatisfied due to the substandard quality of vision imparted. The motivation of the patient behind undergoing the procedure may also play an important role in deciding the postsurgical satisfaction. In our study, majority $(36.67 \%)$ of the patients needed the procedure for improving their marriage prospects. A study carried out by Akhauri et $\mathrm{al}^{8}$ found similar reason amongst the female subjects in the study. This may have led to a good satisfactory score due to minimal preoperative expectations. Likewise, occupation of the patients may also have a bearing on the results.

The incidence of dry eye varies from as less as four percent ${ }^{9}$ to as high as seventy percent. ${ }^{10}$ This dry eye usually may persist for a period of three to six months depending upon the preoperative status of the tear film. Toda et $\mathrm{al}^{11}$ in their study concluded that significant dry eye persisted for at least a month after LASIK surgery. In the current study, the quantitative analysis of the tear film showed a significant reduction in the values of Schirmer's I and Schirmer's II when evaluated on the first follow up after surgery. This returned back to normal in majority of the patients at three months postoperatively. Although, the use of topical artificial tears could have falsely altered the results of tear film evaluation in these patients. Symptoms of dry eye like watering, blurring of vision and foreign body sensation were encountered in $10 \%$ of the patients.

A dramatic improvement in the contrast sensitivity was observed within the first one month after surgery in our patients which remained unchanged at the end of three months. The Contrast Sensitivity Function (CSF) is significantly affected by the pupil size in photopic and mesopic conditions as well as luminance of the room in which the CSF was measured. ${ }^{12,13}$ The neglect of these parameters may question the reliability of the CSF evaluation in our study.

While various objective measures are thus available, a subjective test assembled in the form of a patient based questionnaire would help us quantify the causes of dissatisfaction amongst the patients postoperatively. With a similar view, a patient oriented questionnaire was developed comprising of 14 questions scored as 0,1 and 2 based on whether the patients were unsatisfied, satisfied or very satisfied following surgery. Of the possible maximum score of 28 , the mean preoperative satisfaction score was $16.32 \pm 3.25$ which improved to $22.49 \pm 2.85$ postoperatively. Out of the 150 patients, $93 \%$ of the patients belonged to the satisfied (score 1120) and very satisfied (score of 21-28) groups. Similar results were seen in a study by Brown et $\mathrm{al}^{14}$ who investigated 13,655 patients at 1 month after LASIK procedure. The visual satisfaction in the patients was 95\% while $98.6 \%$ confirmed improved quality of vision. A literature search was conducted retrospectively from 1988 to 2008 by Solomon et al ${ }^{15}$ regarding the outcome of LASIK. Out of the 16.3 million procedures performed worldwide, $95.4 \%$ of patients were satisfied after the surgery.

Out of the parameters tested, night vision problems due to glare and halos after surgery were the major cause of dissatisfaction amongst the patients. Parallel results have been encountered in a study by Tahzib et al. ${ }^{16}$ Several studies have discussed regarding the increased difficulty in night driving amongst the patients postoperatively due to the same reason. ${ }^{17-20}$ These problems are said to diminish six months postoperatively, however our study fails to evaluate the long term modifications in these parameters due to the limited duration of follow up. Appropriate counselling regarding night vision problems is essential in those patients whose occupational requirements include driving at night. Over and above this, difficulty in computer work after the surgery was also encountered as another cause of patient dissatisfaction in our study. However, this can be managed efficiently with the use of topical lubricating eye drops.

Of the various measures, patient counselling is one of the principal modalities that could lead to higher patient satisfaction after surgery. Eydelman et $\mathrm{al}^{21}$ in the PROWL (Patient-Reported Outcomes With LASIK) study pointed out the significance of addressing patient counselling not only towards the side effects but also the possible new symptoms which may develop post LASIK surgery. Moreover, development of intraoperative complications and it's management also pose a noteworthy bearing on the postoperative satisfaction score. Since our study exclusively took into account the uncomplicated LASIK surgeries performed for full correction, a spectrum of postoperative complications which could lead to patients being unsatisfied were disregarded.

\section{Conclusion}

LASIK surgery is one of the commonest refractive surgeries being performed worldwide. A comprehensive preoperative work up along with appropriate patient 
counselling are the keys to setting realistic postsurgical expectations for the patients. Mere improvement in the uncorrected visual acuity should not be made the foundation of assessing the surgical outcome. In the present study, majority of the patients were highly satisfied in terms of the functional gain and visual outcome after the procedure. Night vision complications and dry eye formed the basis for postoperative dissatisfaction.

\section{References}

1. Varley GA, Huang D, Rapuano CJ, Schallhorn S, Wachler BS, Sugar A. LASIK for hyperopia, hyperopic astigmatism, and mixed astigmatism: a report by the American Academy of Ophthalmology. Ophthalmology. 2004;111(8):1604-17.

2. Pillar A, Krueger R. Advances in refractive surgery: June 2014 to July 2015. The Asia-Pacific Journal of Ophthalmology. 2016;5(3):212-22.

3. Hill JC. An informal satisfaction survey of 200 patients after laser in situ keratomileusis. Journal of Refractive Surgery. 2002;18(4):454-9.

4. Tahzib NG, Bootsma SJ, Eggink FA, Nabar VA, Nuijts RM. Functional outcomes and patient satisfaction after laser in situ keratomileusis for correction of myopia. Journal of Cataract \& Refractive Surgery. 2005;31(10):1943-51.

5. Bailey MD, Mitchell GL, Dhaliwal DK, Wachler BS, Zadnik K. Patient satisfaction and visual symptoms after laser in situ keratomileusis. Ophthalmology. 2003;110(7):1371-8.

6. De La Jara PL, Erickson D, Erickson P, Stapleton F. Visual and non-visual factors associated with patient satisfaction and quality of life in LASIK. Eye. 2011;25(9):1194.

7. Sugar A, Rapuano CJ, Culbertson WW, Huang D, Varley GA, Agapitos PJ, de Luise VP, Koch DD. Laser in situ keratomileusis for myopia and astigmatism: safety and efficacy: a report by the American Academy of Ophthalmology. Ophthalmology. 2002;109(1):175-87.

8. Akhaury RK, Verma NP, Kumar R. Patient motivation for laser in situ keratomileusis in the state of Bihar. Journal of Refractive Surgery. 2004;20(5):S727-9.

9. American Academy of Ophthalmology. Basic and Clinical Science Course. Section 13: Refractive Surgery. American Academy of Ophthalmology. 2011-2012.

10. Foster CS, Azar DT, Dohlman CH. Smolin and Thoft's The Cornea. 4th Edition. Philadelphia, PA. Lippincott Williams \& Wilkins; 2005.

11. Toda I, Asano-Kato N, Komai-Hori Y, Tsubota K. Dry eye after laser in situ keratomileusis. American journal of ophthalmology. 2001;132(1):1-7.

12. Montés-Micó R, España E, Menezo JL. Mesopic contrast sensitivity function after laser in situ keratomileusis. Journal of Refractive Surgery. 2003;19(3):353-6.

13. Montés-Micó R, Charman WN. Choice of spatial frequency for contrast sensitivity evaluation after corneal refractive surgery. Journal of Refractive Surgery. 2001;17(6):646-51.

14. Brown MC, Schallhorn SC, Hettinger KA, Malady SE. Satisfaction of 13,655 patients with laser vision correction at 1 month after surgery. Journal of Refractive Surgery. 2009;25(7):S642.

15. Solomon KD, de Castro LE, Sandoval HP, Biber JM, Groat B, Neff KD, Ying MS, French JW, Donnenfeld $\mathrm{ED}$, Lindstrom RL, Force JL. LASIK world literature review: quality of life and patient satisfaction. Ophthalmology. 2009;116(4):691-701.

16. Tahzib NG, Bootsma SJ, Eggink FA, Nabar VA, Nuijts RM. Functional outcomes and patient satisfaction after laser in situ keratomileusis for correction of myopia. Journal of Cataract \& Refractive Surgery. 2005;31(10):1943-51.

17. Bamashmus MA, Hubaish K, Alawad M, Alakhlee H. Functional outcome and patient satisfaction after laser in situ keratomileusis for correction of myopia and myopic astigmatism. Middle East African Journal of Ophthalmology. 2015;22(1):108.

18. Pop M, Payette Y. Risk factors for night vision complaints after LASIK for myopia. Ophthalmology. 2004;111(1):3-10.

19. Collar CV, Gutiérrez R, Jiménez JR, Gonzalez-Méijome JM. Night vision disturbances after successful LASIK surgery. British Journal of Ophthalmology. $2007 \mathrm{Feb} 21$.

20. McGhee CN, Craig JP, Sachdev N, Weed KH, Brown AD. Functional, psychological, and satisfaction outcomes of laser in situ keratomileusis for high myopia. Journal of Cataract \& Refractive Surgery. 2000;26(4):497-509.

21. Eydelman M, Hilmantel G, Tarver ME, Hofmeister EM, May J, Hammel K, Hays RD, Ferris F. Symptoms and satisfaction of patients in the patient-reported outcomes with laser in situ keratomileusis (PROWL) studies. Jama Ophthalmology. 2017;135(1):13-22.

How to cite this article: Patel D. B, Patel A. M, Shah M. A, Vyas A. K, Shah S. Functional outcome and patient satisfaction following LASIK surgery. Indian J Clin Exp Ophthalmol. 2018;4(4):473-477. 